\title{
Overexpression of seven in absentia homolog 2 protein in human breast cancer tissues is associated with the promotion of tumor cell malignant behavior in in vitro
}

\author{
JIE SUN ${ }^{1,2^{*}}$, XIAOJUAN ZHANG ${ }^{3 *}$, YANCHUN HAN $^{4}$, JUAN ZHEN $^{1}$, \\ YUAN MENG $^{1}$ and MIN SONG ${ }^{1}$
}

\begin{abstract}
${ }^{1}$ Department of Pathology, The First Affiliated Hospital and College of Basic Medical Sciences, China Medical University, Shenyang, Liaoning 110001; ${ }^{2}$ Department of Pathology, Central Hospital Affiliated to Shenyang Medical College, Shenyang, Liaoning 110024; ${ }^{3}$ Intensive Care Unit, The First Affiliated Hospital, China Medical University, Shenyang, Liaoning 110001; ${ }^{4}$ Department of Pathology, Binzhou Medical University, Binzhou, Shandong 256603, P.R. China
\end{abstract}

Received January 19, 2016; Accepted February 17, 2016

DOI: $10.3892 / o r .2016 .4976$

\begin{abstract}
Seven in absentia homolog 2 (SIAH2), a homologue of Drosophila seven in absentia (Sina), has emerged as an oncogene and plays important roles in cancer development and

Correspondence to: Dr Min Song, Department of Pathology, The First Affiliated Hospital and College of Basic Medical Sciences, China Medical University, 92 Beier Road, Heping, Shenyang, Liaoning 110001, P.R. China

E-mail: songmin6@sohu.com

"Contributed equally
\end{abstract}

Abbreviations: SIAH, seven in absentia homolog; PKB, protein kinase B; PDK, phosphatidylinositol-dependent kinase; Ras, rat sarcoma; Raf, rapidly accelerated fibrosarcoma; MAPK, mitogen-activated protein kinase; ERK, extracellular signal-regulated kinases; MEK, MAPK/ERK kinase; PI3K, phosphatidylinositol-3-kinase; HIF-1 $\alpha$, hypoxia-inducible factor $1 \alpha$ subunit; VEGF, vascular endothelial growth factor; K-Ras, Kirsten rat sarcoma; HIF, hypoxiainducible factor; VHL, von Hippel-Lindau; IGF, insulin-like growth factor; EGFR, epidermal growth factor receptor; NF- $\mathrm{kB}$, nuclear factor- $\kappa$ B; Spry2, Sprouty2; mTOR, mammalian target of rapamycin; ER, estrogen receptor; PR, progesterone receptor; Her-2, human epidermal growth factor-2; RNAi, ribonucleic acid interference; siRNA, small interference ribonucleic acid; shRNA, short hairpin ribonucleic acid; MTT, 3-(4,5-dimethylthiazol-2-yl)-2,5-diphenyltetrazolium; TBS, Tris-buffered saline; H\&E, hematoxylin and eosin; PBS, phosphate-buffered saline; S-P, streptavidin-peroxidase method; DAB, 3,3'-diaminobenzidine; PAGE, polyacrylamide gel electrophoresis; SDS, sodium dodecyl sulfate; ECL, enhanced chemiluminescence; PI, propidium iodide; BSA, bovine serum albumin; FCM, flow cytometry; SPSS, Statistical Package for Social Science; NBT, normal breast tissues; DCIS, ductal carcinoma in situ; IBC, invasive breast carcinoma

Key words: breast cancer, seven in absentia homolog 2, extracellular signal-regulated kinases, phosphatidylinositol-3-kinase, cell proliferation, invasion progression. This study further assessed the role of SIAH2 in breast cancer and the underlying molecular events. The data showed that SIAH2 protein was overexpressed in invasive breast cancer (IBC) compared to the expression noted in normal or ductal carcinoma in situ (DCIS) tissues, expression of which is associated with malignant behaviors. SIAH2 may function differently in different molecular subtypes (e.g., luminal- vs. basal-like type) of breast cancer. Manipulation of SIAH2 expression led to a 'cross-talk' of the ERK and PI3K pathway, which could be one of the mechanisms by which SIAH2 regulates viability, apoptosis, and invasion capacity in these breast cancer cell lines.

\section{Introduction}

Breast cancer is a major health problem and the leading cause of cancer-related mortality in women. Clinically, breast cancer is a highly heterogeneous adenocarcinoma with various molecular and genetic alterations. For example, Perou et al (1), were the first to carry out a gene expression profile analysis of human breast tissue specimens using gene microarray technology and identified a number of differentially expressed genes associated with breast cancer development. Subsequent studies using cDNA microarray were able to classify breast cancer into four different subtypes: luminal-like, normal breastlike Her-2 overexpression, and basal-like subtype (2,3). Each subtype has unique gene expression characteristics, biological behavior, and clinical prognosis (4). For example, luminal-like breast cancer is characterized by a high level of ER expression and better prognosis, whereas the other three subtypes have negative ER expression. The basal-like breast cancer subtype has a unique phenotype, poorer prognosis, and insensitivity to endocrine and targeted therapy. Thus, research attention has focused on the basal-like subtype of breast cancer.

Basal-like breast cancer accounts for 8-20\% of all invasive breast cancers or $\sim 25 \%$ of advanced and difficult-to-treat breast cancer (5). Clinically, basal-like breast cancer occurs at a relatively young age and often expresses basal-cell cytokeratin subtypes (CK5/6, CK14, and CK17), but does not 
express hormone receptors (ER or PR) or Her-2. Eighty-five percent of tumor tissues have mutated p53 protein and $60 \%$ of cases express epidermal growth factor receptor (EGFR) $(6,7)$, indicating that this subtype of breast cancer has a highly proliferative and invasive clinical behavior with poor survival rate. At the gene level, multiple gene signaling pathways are involved in growth and metastasis of breast cancer, such as the mitogen-activated protein kinase (MEK)-extracellular regulated protein kinase (ERK) pathway and phosphatidylinositol 3-kinase (PI3K)-serine/threonine protein kinase (AKT) pathway (8). The MEK-ERK pathway is closely related to tumor cell proliferation and resistance to apoptosis and, thus, contributes to tumor development and progression, while the PI3K/AKT pathway is one of the main anti-apoptotic mechanisms utilized by tumor cells to create a survival advantage $(9,10)$.

The SIAH family of proteins are homologues of the Drosophila SIAH protein, and humans have two highly conserved SIAHs: SIAH1 and SIAH2 (11). SIAH2, localized at chromosome $3 \mathrm{q} 25$, contains two exons and a $9.8-\mathrm{kb}$ intron and encodes a 324-amino-acid protein (12) that is only expressed in proliferating cells. Schmidt et al (13) showed that the SIAH2 protein is expressed in pancreatic, breast, lung, and cervical cancers and the level of SIAH2 protein is associated with increased tumor malignancy. Thus, SIAH2 is considered to be an oncogene. Recent studies revealed that SIAH2-regulated cell proliferation and apoptosis occur through activation of the ERK pathway (13). Inhibition of SIAH2 activity led to upregulation of Spry2 expression, one of its substrates, and subsequently a decrease in ERK activity $(14,15)$ and inhibition of tumor growth and metastasis. For example, Ahmed et al (15) found that inhibition of SIAH2 expression using SIAH2 shRNA downregulated the level of p-ERK and, thus, inhibited tumor growth and proliferation and promoted apoptosis. Schmidt et al (13) found that inhibition of SIAH2 expression using RNAi inhibited Ras-mediated malignant transformation of fibroblasts and xenograft growth of pancreatic tumor cells in nude mice, and that knockdown of SIAH2 expression in K-Ras-transformed pancreatic tumor cells led to downregulation of the p-ERK level. Thus, in this study, it was hypothesized that SIAH2 or its substrates may be part of the feedback loop of the Ras/Raf/MEK/ERK pathway in breast cancer cells. Therefore, immunohistochemistry, western blotting, and gene knockdown studies were performed to detect SIAH2 expression in basal cell-like and non-basal cell-like breast cancer tissue samples. The effects of SIAH2 knockdown on the regulation of the biological behavior of breast cancer cells and the underlying mechanism were then investigated.

\section{Materials and methods}

Patients and specimens. In this study, a total of 200 cases of breast tissues were retrospectively collected between 2000 and 2009 from the Central Hospital, Shenyang Medical College (Shenyang, China). The study was in compliance with the published Helsinki Declaration and was approved by the Medical Ethics Committee of the Chinese Medical University. Informed consent was obtained prior to surgery from all enrolled patients. The formalin-fixed and paraffin-embedded surgical tissue blocks were retrieved, sectioned, and stained routinely with hematoxylin and eosin (H\&E) and then reviewed by two senior pathologists to carry out a histological diagnosis according to the World Health Organization breast carcinoma histological classification criteria (2012). In addition, 30 cases out of these 155 invasive breast cancer tissues had paired tumor and normal tissues (at least $5 \mathrm{~cm}$ away from the primary tumor lesion) and were flash-frozen in liquid nitrogen and stored in a $-80^{\circ} \mathrm{C}$ freezer until protein extraction.

Immunohistochemistry. Four-micron-thick sections were prepared for immunostaining with a streptavidin-peroxidase (S-P) method (Ultrasensitive; Maixin, Fuzhou, China) according to the manufacturer's instructions. The primary antibody used was a monoclonal mouse anti-SIAH2 antibody (1:200; Santa Cruz Biotechnology, Santa Cruz, CA, USA). The colorimetric reaction was performed using 3,3-diaminobenzidine tetrahydrochloride (DAB; Maixin). For the negative control, the primary antibody was replaced with a non-immunized normal goat serum. The stained tissue sections were reviewed and scored by two pathologists independently; brown particles appearing in the nucleus were regarded as positive staining of the cell. The intensity of immunostaining was scored as 1 , weak; 2 , moderate; and 3, intense and the percentage of positive cells as $0 \%$, negative; $1-50 \%, 1 ; 51-75 \%$, $2 ; \geq 76 \%, 3$. Scoring was determined from at least five high power fields (x400 magnification). The scores of each sample were multiplied to reach a final score of $0,1,2,3,4,6$, or 9 , and the tissues were determined as negative if the final score was $<4$ and positive if the score was $\geq 4$.

Cell lines and culture. Human breast cancer MDA-MB-231 and MCF-7 cell lines and normal human mammary epithelial cell line MCF-10A were obtained from the American Type Culture Collection (ATCC; Manassas, VA, USA). MDA-MB-231 cells were maintained in Leibovitz L-15 medium with $10 \%$ fetal bovine serum (FBS), and MCF-7 cells in Dulbecco's modified Eagle's medium (DMEM) with $10 \%$ FBS, while MCF-10A cells were maintained in DMEM with 5\% FBS, $10 \mu \mathrm{g} / \mathrm{ml}$ insulin, and $20 \mathrm{ng} / \mathrm{ml}$ EGF in a humidified incubator with $5 \% \mathrm{CO}_{2}$ at $37^{\circ} \mathrm{C}$.

According to previous studies of gene expression profiling and gene copy number $(1,16-20)$, MDA-MB-231 cells belong to the basal-like subtype of breast cancer cells, while MCF-7 cells represent luminal breast cancer cells.

Construction of vectors, transient gene transfection, and treatment with ERK and PI3K inhibitors. The SIAH2 expression vector pcDNA3.1-flag-SIAH2 and pcDNA3.1-flag empty vector were kindly provided by Dr Ze'ev Ronai of The Burnham Institute (La Jolla, CA, USA). SIAH2 shRNA and the negative control shRNA were purchased from Santa Cruz Biotechnology. For transient gene transfections, cells were grown and transfected with pcDNA3.1-flag-SIAH2, pcDNA3.1-flag, SIAH2 shRNA, or control shRNA using Attractene or HiperFect (both from Qiagen) following the manufacturer's instructions. Afterwards, the cells were subjected to western blotting and the transfected cells were also subjected to treatment with ERK (PD98059) or PI3K (LY294002) (both from Sigma, St. Louis, MO, USA) inhibitor at $10 \mu \mathrm{mol} / 1$ for $24 \mathrm{~h}$. 
Protein extraction and western blotting. Total cellular protein was extracted using lysis buffer and the supernatants were collected by centrifugation of the cell lysis at 15,000 rpm for $30 \mathrm{~min}$ at $4^{\circ} \mathrm{C}$. The protein lysis was boiled for $5 \mathrm{~min}$ and $60 \mu \mathrm{g}$ from each protein sample each was separated on a $12 \%$ sodium dodecyl sulfate-polyacrylamide gel electrophoresis (SDS-PAGE) gel and transferred onto PVDF membranes. After blocking with $5 \%$ skim milk solution in PBS, the membranes were incubated with a primary antibody against SIAH2 (at a dilution of 1:200), p-ERK (1:400), p-AKT (1:400), or $\beta$-actin (1:200) overnight at $4^{\circ} \mathrm{C}$. Afterwards, membranes were incubated with each corresponding secondary antibody at room temperature for $2 \mathrm{~h}$. The protein bands were visualized using an enhanced chemiluminescence (ECL) kit and then quantified using EC3 imaging system (UVP, LLC). The gray scale values of each protein band were normalized to the values of the corresponding $\beta$-actin band. The experiments were repeated once independently.

Cell viability MTT assay. The transfected cells were seeded in 96-well plates at $1 \times 10^{4}$ cells/well and the cell viability was evaluated using the MTT assay. The absorbance, which was directly proportional to the number of living cells in culture, was measured at $490 \mathrm{~nm}$ using a microplate reader. A blank with dimethyl sulfoxide alone was measured and subtracted from all values. The experiments were performed in triplicate and repeated at least three times independently.

Tumor cell Matrigel invasion assay. Cell invasive ability was assessed using a 24 -well Transwell with $8-\mu \mathrm{m}$ pore polycarbonate membrane inserts. Matrigel $(100 \mu \mathrm{g} / \mathrm{ml}$ at dilution of $1: 7$ with cell culture medium) was applied to the upper surface of the membranes. After transfection for $24 \mathrm{~h}$, cells were seeded in the upper chamber at a density of $5 \times 10^{4}$ cells/well and the bottom of the chamber was filled with cell culture medium with $20 \%$ FBS Next the plates were incubated for $24 \mathrm{~h}$. At the end of the experiments, cells that had invaded into the surface of the membrane were fixed with methanol and stained with hematoxylin. Five high-magnification microscope fields were randomly selected per filter to count the number of invaded cells.

Flow cytometric apoptosis assay. Annexin V/FITC double staining was carried out as described by the manufacturer (Invitrogen, Carlsbad, CA, USA). Cells were immediately analyzed by flow cytometry and quantified using CellQuest software (both from BD Biosciences) for the percentage of apoptotic cells in each experimental group.

Statistical analysis. All statistical calculations were performed by SPSS version 13.0 for Windows software (SPSS, Chicago, IL, USA). The $\chi^{2}$ test and one-way analysis of variance (ANOVA) were performed to assess statistically significant differences between groups of tissues or cell treatments. A $\mathrm{P}<0.05$ was considered statistically significant.

\section{Results}

Characteristics of the patients. The 200 breast cancer cases included 10 normal breast tissues (NBTs), 35 ductal carcinoma in situ (DCIS) tissues, and 155 invasive breast carcinoma (IBC)
Table I. Association of SIAH2 expression with clinicopathological factors in 155 invasive breast carcinomas.

\begin{tabular}{|c|c|c|c|c|}
\hline \multirow{2}{*}{$\begin{array}{l}\text { Clinicopathological } \\
\text { factors }\end{array}$} & \multirow[b]{2}{*}{$\mathrm{N}$} & \multicolumn{2}{|c|}{ SIAH2 expression } & \multirow[b]{2}{*}{ P-value } \\
\hline & & Positive & Negative & \\
\hline Age (years) & & & & 0.883 \\
\hline$<50$ & 56 & 27 & 29 & \\
\hline$\geq 50$ & 99 & 51 & 48 & \\
\hline Tumor size (mm) & & & & 0.693 \\
\hline$<25$ & 87 & 45 & 42 & \\
\hline$\geq 25$ & 68 & 33 & 35 & \\
\hline Nuclear grade & & & & 0.000 \\
\hline $\mathrm{I}$ & 17 & 3 & 14 & \\
\hline II & 60 & 21 & 39 & \\
\hline III & 78 & 54 & 24 & \\
\hline Tumor stage & & & & 0.572 \\
\hline I & 40 & 18 & 22 & \\
\hline II & 81 & 44 & 37 & \\
\hline III & 34 & 16 & 18 & \\
\hline $\begin{array}{l}\text { Lymph node } \\
\text { metastasis }\end{array}$ & & & & 0.284 \\
\hline No & 90 & 42 & 48 & \\
\hline Yes & 65 & 36 & 29 & \\
\hline Genotyping & & & & 0.000 \\
\hline Basal-like & 28 & 25 & 3 & \\
\hline Luminal A & 49 & 9 & 40 & \\
\hline Luminal B & 10 & 5 & 5 & \\
\hline Her-2 & 22 & 15 & 7 & \\
\hline Null & 46 & 24 & 22 & \\
\hline
\end{tabular}

tissues. Among the 155 IBCs, 74\% (115/155) were invasive ductal carcinomas, $12 \%(18 / 155)$ were invasive lobular carcinomas, $10 \%(15 / 155)$ were medullary carcinomas, and $4 \%$ (7/155) were of other histological types. Clinicopathological data and expression of p53 and Ki67 proteins were also collected. In brief, the median age of the patients was 50 years old (ranging between 28 and 84 years) and the median tumor size was $25 \mathrm{~mm}$ (ranging between 6 and $90 \mathrm{~mm}$ ) (Table I). Moreover, 28 patients were identified as basal-like breast cancers by immunohistochemistry on the basis of Nielsen's (21) method. Specifically, the basal-like breast cancers often express high molecular weight basal cytokeratin (CK5/6, CK14, and CK17) and/or EGFR, while they do not express hormone receptors [estrogen receptor (ER) and progesterone receptor (PR)] or Her-2/neu. However, according to Nielsen's criteria, the 155 breast cancer cases were categorized into five intrinsic subgroups: the basal-like group (ER ${ }^{-}, \mathrm{HER}-2^{-}, \mathrm{CK} 5 / 6^{+}$and/or $\mathrm{EGFR}^{+}$), the luminal A group ( $\mathrm{ER}^{+}$and HER-2-), the luminal B group $\left(\mathrm{ER}^{+}\right.$and Her-2 $2^{+}$, the Her-2 group (ER- and Her- $\left.2^{+}\right)$and the negative (null) group (ER', Her-2', CK5/6- and EGFR').

Differential expression of SIAH2 protein in breast cancer tissues and cell lines. SIAH2 protein was expressed in the 
Table II. Differential expression of the SIAH2 protein in breast tissues $(n=200)$.

\begin{tabular}{|c|c|c|c|c|c|c|}
\hline \multirow[b]{2}{*}{ Diagnosis } & \multirow[b]{2}{*}{$\mathrm{N}$} & \multirow[b]{2}{*}{$\begin{array}{c}\text { Mean of IS } \\
\text { staining score }\end{array}$} & \multirow[b]{2}{*}{ P-value } & \multicolumn{2}{|c|}{ SIAH2 expression } & \multirow[b]{2}{*}{ P-value } \\
\hline & & & & $\begin{array}{c}\text { Low }(\mathrm{IS}<4) \\
\text { n/total }(\%)\end{array}$ & $\begin{array}{c}\text { High }(\mathrm{IS} \geq 4) \\
\text { n/total }(\%)\end{array}$ & \\
\hline NBT & 10 & $1.10 \pm 1.45$ & 0.000 & 10/10 (100) & $0 / 10(0)$ & 0.000 \\
\hline DCIS & 35 & $2.03 \pm 1.52$ & & $30 / 35(85.71)$ & $5 / 35(14.29)$ & \\
\hline IBC & 155 & $4.01 \pm 1.60$ & & 77/155 (49.68) & $78 / 155(50.32)$ & \\
\hline
\end{tabular}
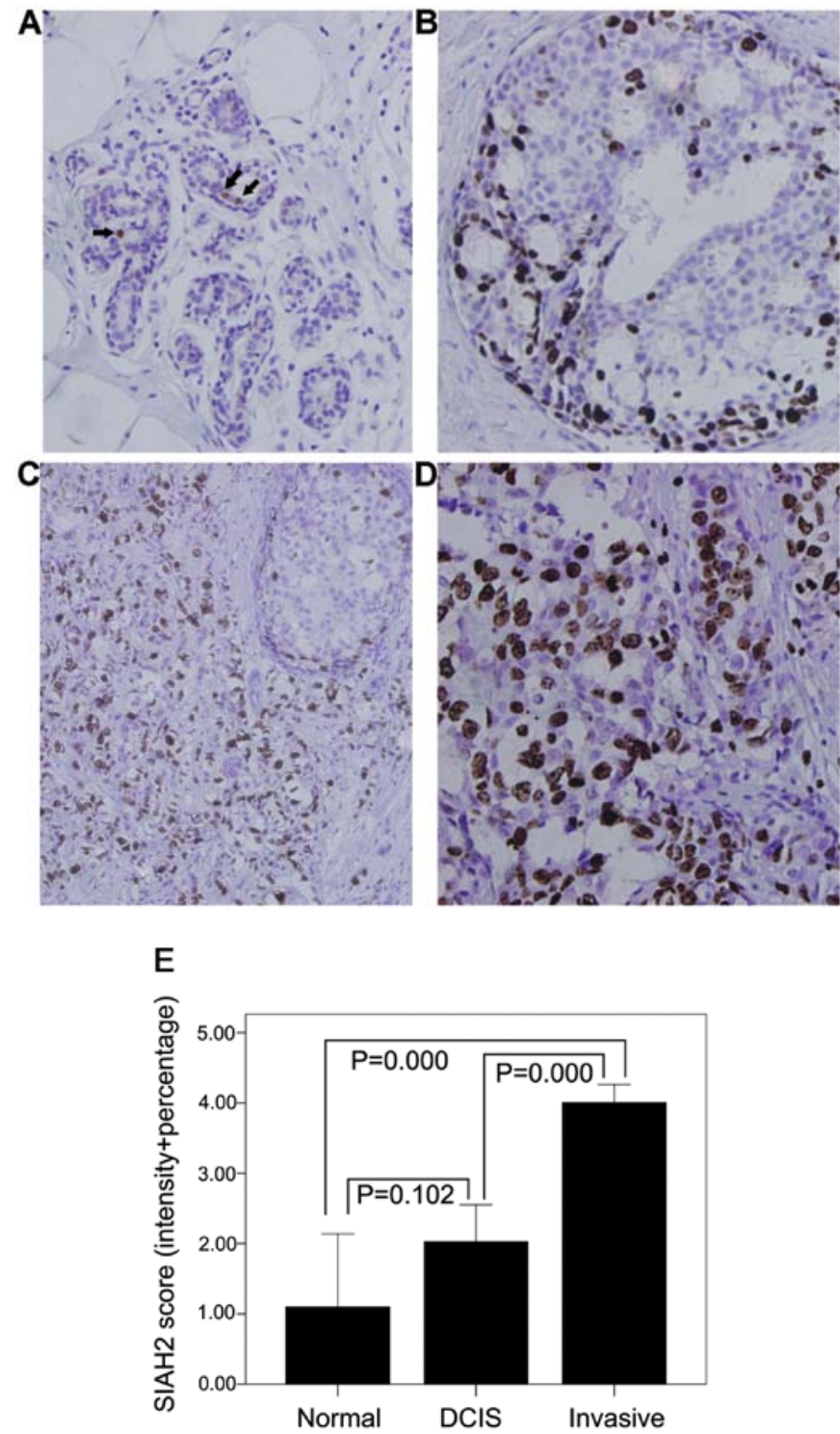

Figure 1. Differential expression of SIAH2 protein in breast tissues detected by immunohistochemistry. (A) Occasional SIAH2 nuclear positivity (arrows) was observed in the luminal cells in the terminal duct lobular unit (original magnification, $\mathrm{x} 400$ ). (B) Strong staining of SIAH2 protein in the nuclei of ductal carcinoma in situ (original magnification, $\mathrm{x} 400$ ). (C) SIAH2 nuclear positivity occurs in few cells in ductal carcinoma in situ, whereas the adjacent invasive breast cancer cells have strong and diffuse SIAH2 immunoreactivity (original magnification, x200). (D) Strong and diffuse staining of SIAH2 in the nuclei of invasive breast cancer cells (original magnification, x400). (E) Semi-quantitative SIAH2 expression in normal, ductal carcinoma in situ (DCIS), and invasive carcinoma samples, which shows that there was a non-significant increase in SIAH2 from the transition of normal to in situ disease $(\mathrm{P}=0.102)$ and a significant increase in $\mathrm{SIAH} 2$ from in situ to invasive breast carcinoma $(\mathrm{P}=0.000)$. nuclei of occasional cells within the luminal layer of ducts and acini in normal mammary glands in 4 out of the 10 cases (40\%). The level of SIAH2 expression was usually of mild to moderate intensity and, if used as a cut-off point for the tumor tissues, SIAH2 expression was considered negative in normal tissues (Fig. 1A). SIAH2 expression was positive and of moderate to strong intensity with a homogeneous distribution in the nuclei of 5 out of 35 (14.29\%) DCIS cases (Fig. 1B and C). In contrast, the SIAH2 protein was expressed in $50.32 \%(78 / 155)$ of invasive breast carcinoma tissues with the majority of a strong intensity (Fig. 1C and D). SIAH2 expression was significantly upregulated in IBCs compared to normal or DCIS tissues $(\mathrm{P}=0.000$; Table II and Fig. 1E), whereas there was no significance between normal and DCIS tissues $(\mathrm{P}=0.102)$. Our western blot data also confirmed upregulation of SIAH2 expression in IBCs compared to the paired distant normal tissues $(t=6.558$, $\mathrm{P}=0.000$; Fig. 2A).

Association of SIAH2 expression with clinicopathological data and p53 and Ki67 expression. Next, the association of SIAH2 expression with clinicopathological data and p53 and Ki67 expression was investigated in the 155 IBC cases. The data showed that SIAH2 expression was associated with a higher tumor nuclear grade and molecular classification of breast cancer subtypes. Moreover, SIAH2 expression was associated with p53 and Ki67 expression and inversely associated with lymph node metastasis in basal-like IBC. In the luminal A and null subtype of IBC, SIAH2 expression was associated with Ki67 expression (Tables I, III and V). However, there was no association found between SIAH2 expression and other clinicopathological data.

Change in breast cancer cell malignant behaviors after knockdown of SIAH2 expression. According to the genotyping and gene expression analysis by Neve et al (18), MCF-7 breast cancer cells were chosen as a luminal breast cancer cell line and MDA-MB-231 cells as a basal-like type of breast cancer in the current study. A MCF-10A normal mammary epithelial cell line was used as a control. It was found that the SIAH2 protein was highly expressed in the MDA-MB-231 and MCF-7 cells, whereas the MCF-10A cell line had a very low expression level of SIAH2 protein $(\mathrm{P}<0.05$; Fig. 2B). MDA-MB-231 cells expressed a much higher level of SIAH2 protein than MCF-7 cells ( $\mathrm{P}<0.05$, Fig. 2B).

Next, the effects of SIAH2 expression and knockdown on the regulation of breast cancer cell proliferation and 

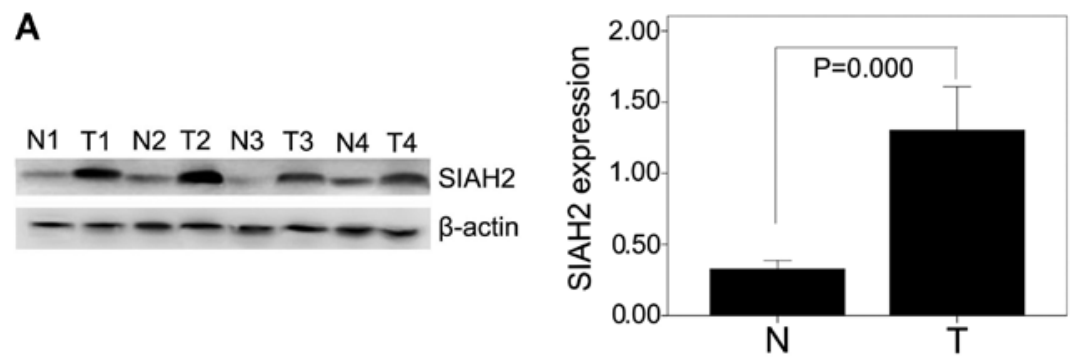

B
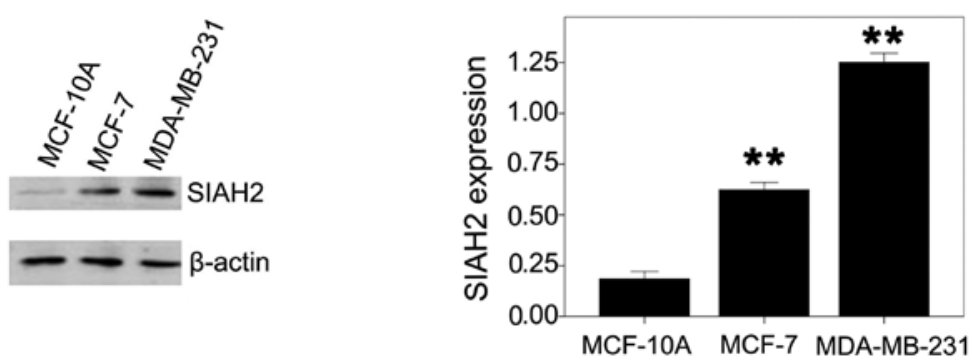

Figure 2. Western blot analysis of SIAH2 protein expression in breast tissues and cell lines. (A) SIAH2 expression was higher in tumorous (T) tissues compared to non-tumorous $(\mathrm{N})$ tissues from the same patient $(\mathrm{t}=6.558, \mathrm{P}=0.000)$. (B) SIAH2 expression was higher in the MDA-MB-231 and MCF-7 human breast cancer cell lines than in the MCF-10A human normal breast epithelial cell line. SIAH2 expression was higher in the MDA-MB-231 basal-like breast cancer cell line than in the MCF-7 luminal breast cancer cell line. ${ }^{* *} \mathrm{P}<0.01$.

Table III. Association of SIAH2 expression with p53 level in each subtype of breast cancer.

\begin{tabular}{|c|c|c|c|c|}
\hline & $\begin{array}{l}\text { SIAH2 } \\
\text { positive }\end{array}$ & $\begin{array}{c}\text { SIAH2 } \\
\text { negative }\end{array}$ & $\begin{array}{c}\text { Spearman's } \\
\text { correlation } \\
\left(r_{s}\right)\end{array}$ & P-value \\
\hline \multicolumn{5}{|c|}{ Basal-like } \\
\hline $\mathrm{p} 53^{+}$ & 20 & 0 & 0.548 & \\
\hline $\mathrm{p} 53^{-}$ & 5 & 3 & & 0.017 \\
\hline \multicolumn{5}{|c|}{ Luminal A } \\
\hline $\mathrm{p} 53^{+}$ & 2 & 5 & 0.108 & \\
\hline p53- & 7 & 35 & & 0.598 \\
\hline \multicolumn{5}{|c|}{ Luminal B } \\
\hline $\mathrm{p} 53^{+}$ & 2 & 1 & 0.218 & \\
\hline p53- & 3 & 4 & & 1.00 \\
\hline \multicolumn{5}{|l|}{ Her-2 } \\
\hline $\mathrm{p} 53^{+}$ & 6 & 2 & 0.111 & \\
\hline p53- & 9 & 5 & & 0.671 \\
\hline \multicolumn{5}{|l|}{ Null } \\
\hline $\mathrm{p} 53^{+}$ & 10 & 9 & 0.008 & \\
\hline p53- & 14 & 13 & & 1.00 \\
\hline
\end{tabular}

invasion capacity was investigated by transient transfection of pcDNA3.1-flag-SIAH2 and SIAH2 siRNA, respectively, into breast cancer cell lines. Western blotting data showed SIAH2 expression or knockdown in breast cancer cell lines (Fig. 3A). A tumor cell invasion assay showed that knockdown of SIAH2 expression in the MDA-MB-231 cells with high SIAH2 expression resulted in induction of tumor cell invasion capacity, whereas restoration of SIAH2 expression in the MCF-7 cells reduced tumor cell invasion (Fig. 3B).
Table IV. Association of SIAH2 expression with Ki67 level in each subtype of breast cancer.

\begin{tabular}{|c|c|c|c|c|}
\hline & $\begin{array}{l}\text { SIAH2 } \\
\text { positive }\end{array}$ & $\begin{array}{c}\text { SIAH2 } \\
\text { negative }\end{array}$ & $\begin{array}{c}\text { Spearman's } \\
\text { correlation } \\
\left(r_{s}\right)\end{array}$ & P-value \\
\hline \multicolumn{5}{|c|}{ Basal-like } \\
\hline $\mathrm{Ki} 67^{+}$ & 24 & 1 & 0.627 & \\
\hline Ki67- & 1 & 2 & & 0.023 \\
\hline \multicolumn{5}{|c|}{ Luminal A } \\
\hline $\mathrm{Ki} 67^{+}$ & 9 & 7 & 0.681 & \\
\hline $\mathrm{Ki}^{-} 7^{-}$ & 0 & 33 & & 0.000 \\
\hline \multicolumn{5}{|c|}{ Luminal B } \\
\hline $\mathrm{Ki} 67^{+}$ & 5 & 3 & 0.500 & \\
\hline $\mathrm{Ki}^{-} 7^{-}$ & 0 & 2 & & 0.444 \\
\hline \multicolumn{5}{|l|}{ Her-2 } \\
\hline $\mathrm{Ki} 67^{+}$ & 14 & 5 & 0.297 & \\
\hline $\mathrm{Ki} 67^{-}$ & 1 & 2 & & 0.227 \\
\hline \multicolumn{5}{|l|}{ Null } \\
\hline $\mathrm{Ki}^{+} 7^{+}$ & 23 & 4 & 0.788 & \\
\hline $\mathrm{Ki}^{-} 7^{-}$ & 1 & 18 & & 0.0001 \\
\hline
\end{tabular}

Furthermore, knockdown of SIAH2 expression reduced the viability of breast cancer MDA-MB-231 cells, whereas overexpression of SIAH2 protein also reduced cell viability in the MCF-7 luminal-like breast cancer cell line (Fig. 3C).

Additionally, the underlying mechanism for the different roles of the SIAH2 protein in the various breast cancer cells was explored. Our data showed that the MDA-MB-231 cells had a higher level of p-ERK, EGFR and HIF-1 $\alpha$ expression, but a lower level of p-AKT than the MCF-7 cells (Fig. 4). 
A
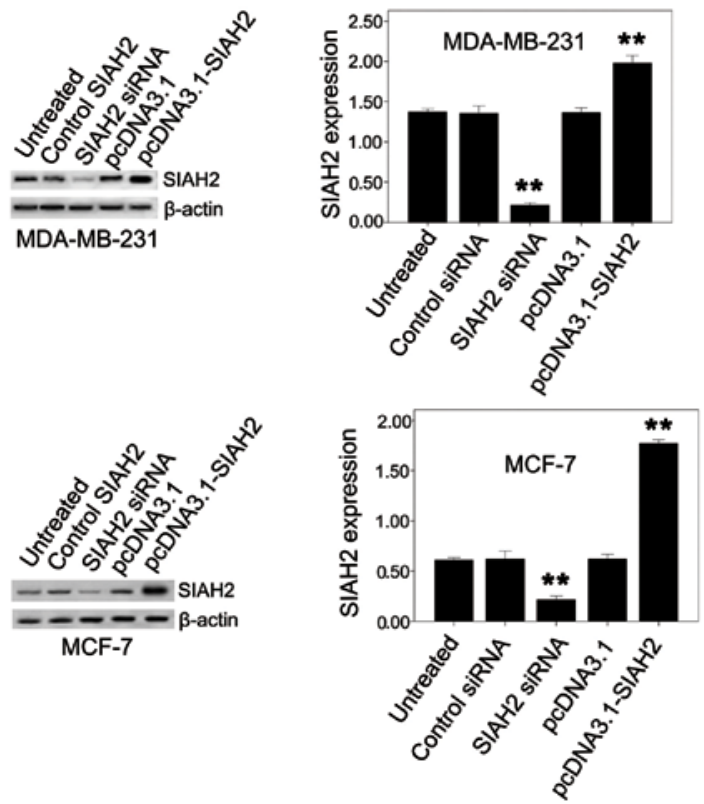

B
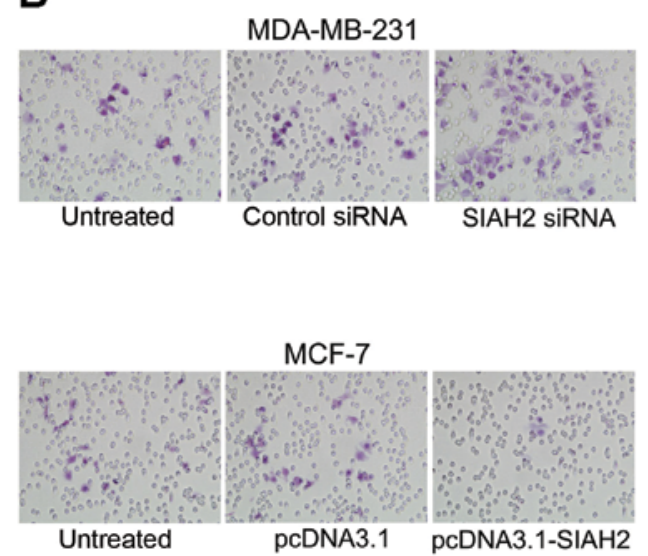
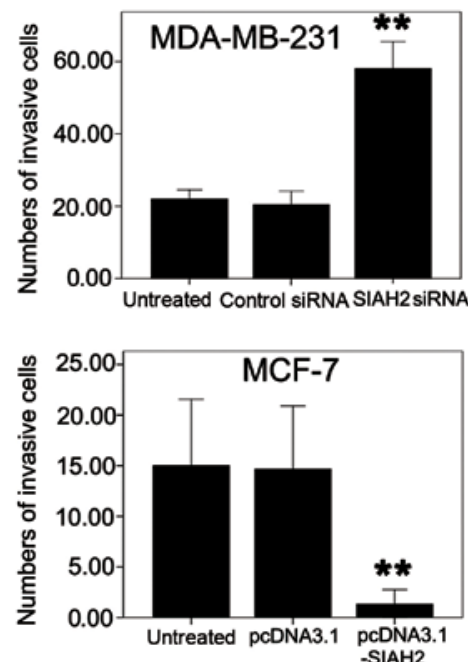

C

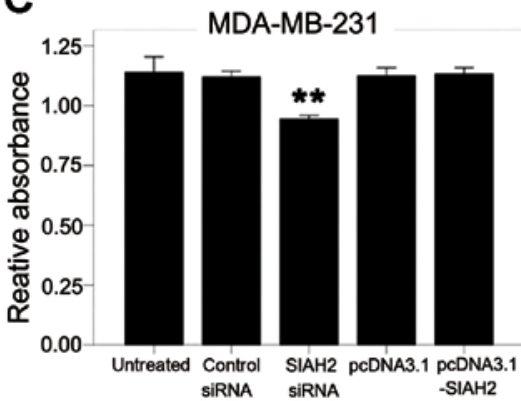

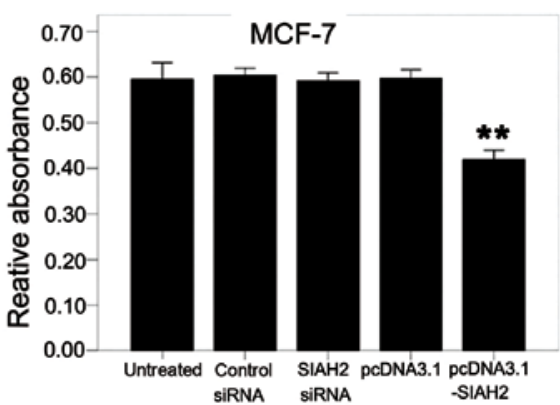

Figure 3. Effect of SIAH2 overexpression or knockdown on regulation of SIAH2 expression, tumor cell viability and invasion capacity in breast cancer cells (A) Western blot analysis. The level of SIAH2 was overexpressed in cells transfected with PcDNA3.1-flag-SIAH2, but decreased in cells transfected with the SIAH2 siRNA. (B) Tumor cell invasion assay. Knockdown of SIAH2 expression promoted invasion capacity of the MDA-MB-231 basal-like breast cancer cell line, whereas overexpression of SIAH2 protein inhibited invasion capacity of the MCF-7 luminal-like breast cancer cell line. (C) MTT cell viability assay. Knockdown of SIAH2 expression suppressed cell viability, but overexpression of SIAH2 protein had no effect on cell viability in the MDA-MB-231 basal-like breast cancer cell line. Knockdown of SIAH2 expression had no effect on cell viability, whereas overexpression of SIAH2 protein suppressed cell viability in the MCF-7 luminal-like breast cancer cell line. ${ }^{* *} \mathrm{P}<0.01$

'Cross-talk' between the ERK and PI3K pathways in breast cancer cell lines. To investigate the effect of SIAH2 on regulation of p-ERK, p-AKT and HIF-1 $\alpha$ expression, SIAH2 shRNA or pcDNA3.1-flag-SIAH2 was transfected into the breast cancer cell lines. Overexpression of SIAH2 in the
MDA-MB-231 cell line had no effect on p-ERK, p-AKT or HIF-1 $\alpha$ expression, whereas knockdown of SIAH 2 expression was able to reduce the level of p-ERK, but induced the levels of p-AKT and HIF-1 $\alpha$. In contrast, overexpression of SIAH2 protein in the MCF-7 cell line increased the p-ERK level, but 

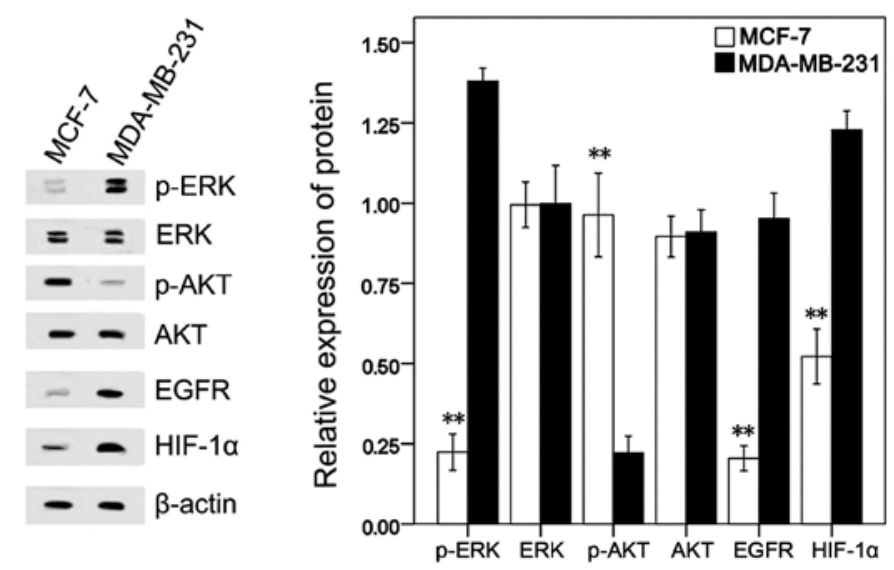

Figure 4. Expression of different proteins in breast cancer cells. Results showed that MDA-MB-231 cells expressed higher levels of p-ERK, EGFR and HIF-1 $\alpha$, but a lower level of p-AKT compared to the MCF-7 cells. ${ }^{* *} \mathrm{P}<0.01$.

Table V. Association of SIAH2 expression with tumor lymph node metastasis in each subtype of breast cancer.

\begin{tabular}{|c|c|c|c|c|}
\hline & SIAH2 positive & SIAH2 negative & Spearman's correlation $\left(r_{s}\right)$ & P-value \\
\hline \multicolumn{5}{|l|}{ Basal-like } \\
\hline Lymph node metastasis positive & 6 & 3 & -0.503 & \\
\hline Lymph node metastasis negative & 19 & 0 & & 0.026 \\
\hline \multicolumn{5}{|l|}{ Luminal A } \\
\hline Lymph node metastasis positive & 3 & 14 & -0.014 & \\
\hline Lymph node metastasis negative & 6 & 26 & & 1.00 \\
\hline \multicolumn{5}{|l|}{ Luminal B } \\
\hline Lymph node metastasis positive & 3 & 2 & 0.200 & \\
\hline Lymph node metastasis negative & 2 & 3 & & 1.00 \\
\hline \multicolumn{5}{|l|}{ Her-2 } \\
\hline Lymph node metastasis positive & 12 & 4 & 0.239 & \\
\hline Lymph node metastasis negative & 3 & 3 & & 0.334 \\
\hline \multicolumn{5}{|l|}{ Null } \\
\hline Lymph node metastasis positive & 12 & 6 & 0.233 & \\
\hline Lymph node metastasis negative & 12 & 16 & & 0.14 \\
\hline
\end{tabular}

decreased the p-AKT and HIF-1 $\alpha$ levels, whereas knockdown of SIAH2 expression slightly decreased p-ERK expression, but had no effects on the p-AKT level (Fig. 5A).

To determine the relationship between the ERK and PI3K pathways in the breast cancer cells, the cells were transfected with SIAH2 shRNA and then treated with p-ERK and/or PI3K inhibitor (PD98059 and/or LY294002, respectively). The results showed that, in the MDA-MB-231 basal-like breast cancer cell line, inhibition of SIAH2 expression or blocking the activity of the ERK pathway caused negative feedback activation of the PI3K pathway (Fig. 5B). Similarly, in the MCF-7 luminal breast cancer cell line, blockage of the PI3K pathway caused negative feedback activation of the ERK pathway (Fig. 5B).

Effects of SIAH2 on regulation of breast cancer cell invasion capacity through feedback activation/inhibition of the PI3K pathway. Next, the effects of SIAH2 on regulation of breast cancer cell invasion capacity and the underlying molecular events were assessed. An invasion assay showed that the invasion capacity of the MDA-MB-231 cells was increased after knockdown of SIAH2 expression, whereas the invasion capacity of the MCF-7 cells was decreased after transfection with SIAH2 cDNA. We speculate that these results can be partially explained by the feedback activation of the PI3K pathway and increased expression of HIF- $1 \alpha$ after SIAH2 silencing, or blockage of the PI3K pathway and a decrease in HIF-1 $\alpha$ expression due to overexpression of SIAH2.

To prove whether the increase in tumor cell invasion ability after knockdown of SIAH2 expression was caused by feedback activation of the PI3K pathway in the MDA-MB-231 cell line, the cells were treated with SIAH2 siRNA and PI3K inhibitor (LY294002) simultaneously. The data showed that the induced tumor cell invasion capacity after SIAH2 knock- 
A

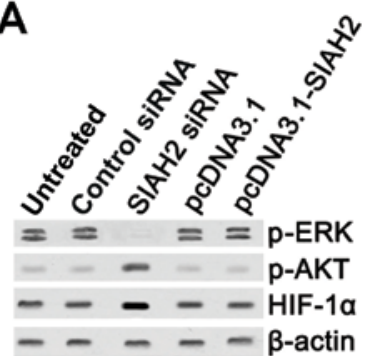

MDA-MB-231

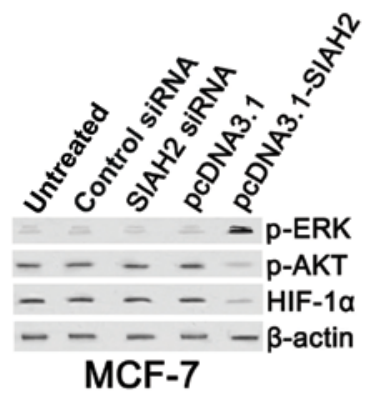

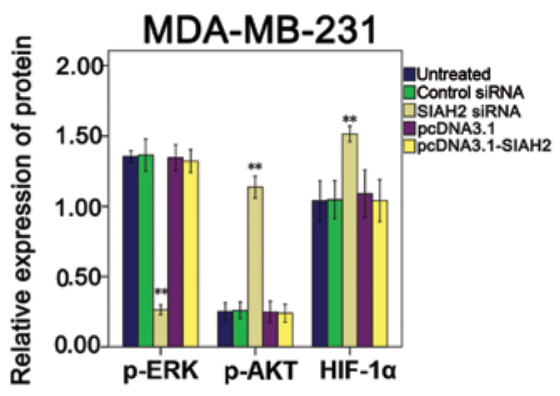

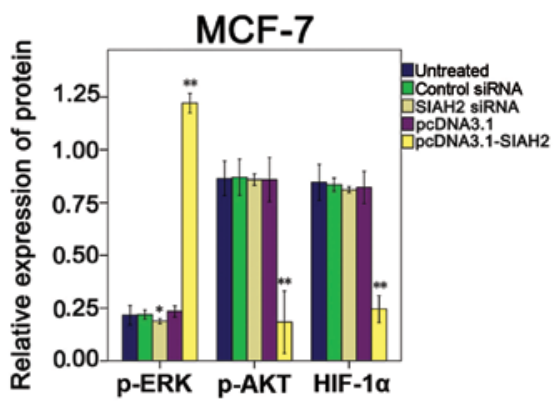

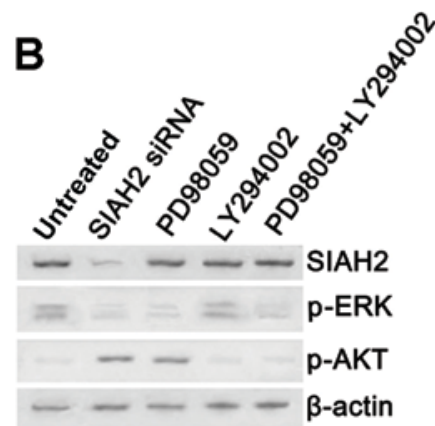
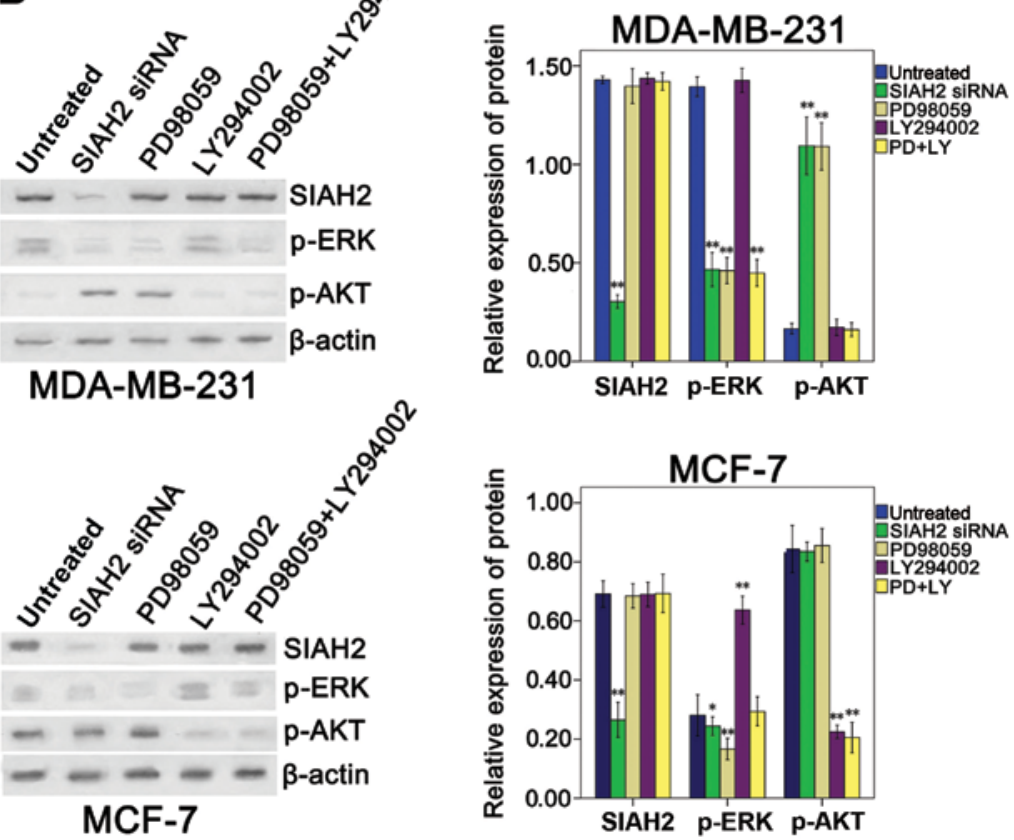

Figure 5. Effect of SIAH2 overexpression or knockdown and treatment with ERK or PI3K inhibitors on the regulation of SIAH2 and other gene expression in breast cancer cells. (A) Western blot analysis. MDA-MB-231 or MCF-7 cells were transfected with SIAH2 cDNA or shRNA and then subjected to western blotting. (B) Western blotting. MDA-MB-231 or MCF-7 cells were transfected with SIAH2 siRNA and treated with the ERK (PD98059) or PI3K inhibitor (LY294002) and then subjected to western blotting. ${ }^{*} \mathrm{P}<0.05 ;{ }^{* *} \mathrm{P}<0.01$.

down was reversed by treatment with the PI3K inhibitor in the MDA-MB-231 cells (Fig. 6A). In contrast, treatment with LY294002 alone had no effect on MDA-MB-231 cell invasion capacity (Fig. 6B).

Similarly, in the MCF-7 cells, SIAH2 overexpression and treatment with the ERK inhibitor (PD98059) simultaneously recovered p-AKT expression and activity of the PI3K pathway activity (Fig. 6A); thus, tumor cell invasion capacity was also recovered (Fig. 6B). These data indicate that the effects of SIAH2 on the regulation of breast cancer cell invasion capacity occurred through feedback activation/inhibition of the PI3K pathway.
Effect of SIAH2 shRNA and ERK and PI3K inhibitors on regulation of cell viability. Next, the effect of SIAH2 on the regulation of cell viability in the MDA-MB-231 and MCF-7 cells was assessed. MTT data showed that knockdown of SIAH2 expression suppressed MDA-MB-231 cell viability, whereas overexpression of SIAH2 protein did not affect cell viability. In contrast, knockdown of SIAH2 expression did not significantly affect MCF-7 cell viability, but overexpression of SIAH2 protein decreased MCF-7 cell viability. Furthermore, MDA-MB-231 cell viability was decreased after treatment with the p-ERK inhibitor (PD98059) and addition of SIAH2 siRNA, while addition of the PI3K inhibitor (LY294002) had no effect 
A
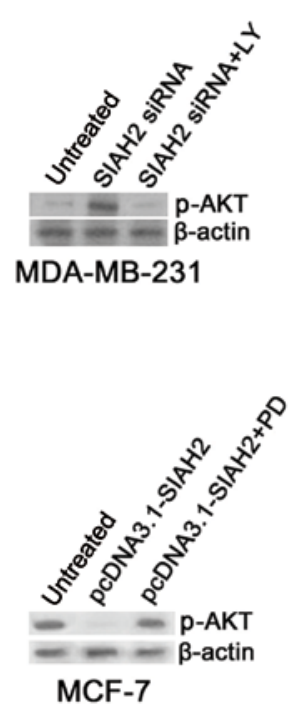
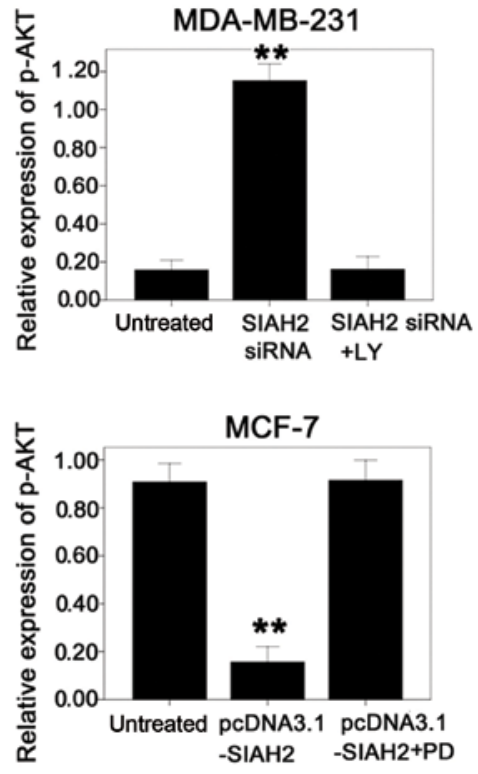

B
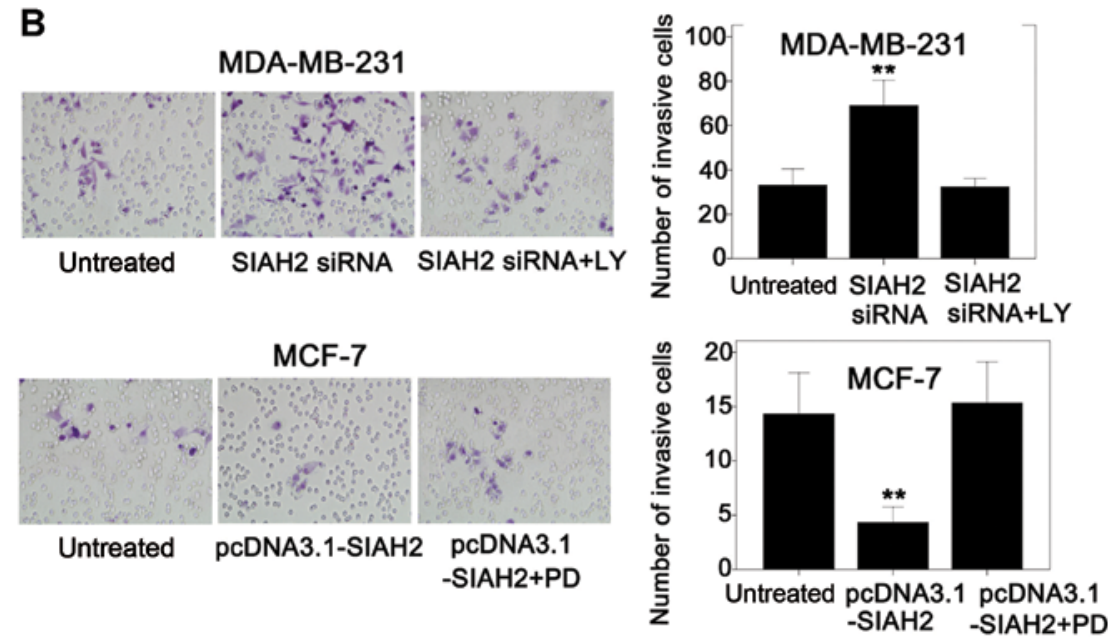

Figure 6. Effect of SIAH2 knockdown or treatment with the ERK or PI3K inhibitors on the regulation of cell viability and invasion capacity of breast cancer cells. (A) Tumor cells were transfected with SIAH2 siRNA and treated with the ERK (PD98059) or PI3K inhibitor (LY294002) and then subjected to western blot analysis. (B) Tumor cells were transfected with SIAH2 siRNA and treated with the ERK (PD98059) or PI3K inhibitor (LY294002) and then subjected to a tumor cell invasion assay. ${ }^{* *} \mathrm{P}<0.01$.

on MDA-MB-231 cell viability. Upon combined treatment with these two inhibitors (PD98059 and LY294002), MDA-MB-231 cell viability was significantly suppressed (Fig. 7). This result could be due to feedback activation of the PI3K pathway after knockdown of SIAH2 expression or inhibition of the ERK pathway by PD98059 treatment. The PI3K pathway could mediate the biological effects on inhibition of apoptosis, which partly counteracted the effects on inhibition of cell proliferation caused by SIAH2 knockdown or PD98059 treatment. Addition of these two inhibitors (PD98059 and LY294002) together terminated the decreased apoptosis by activation of the PI3K pathway. Therefore, MDA-MB-231 cell viability was slightly reduced after addition of SIAH2 siRNA $(0.93 \pm 0.017)$ or PD98059 $(1.10 \pm 0.018$ in LY294002-treated cells vs. PD98059-only-treated cells $(0.9487 \pm 0.025)$ and control cells $(1.133 \pm 0.021)$. Cell viability was significantly reduced after addition of these two inhibitors (PD98059 and LY294002) together $(1.10 \pm 0.018$ in LY294002-treated cells or $0.14 \pm 0.014$ in LY294002- and PD98059-treated cells vs. 1.133 \pm 0.025 in control cells). However, in the MCF-7 cells, addition of PD98059 had no significant effect on cell viability, but addition of LY294002 significantly decreased cell viability. The combination of these two inhibitors (PD98059 and LY294002) caused the same degree of cell proliferation reduction as LY294002 alone (Fig. 7), indicating that there was no effect on cell viability after activation of the ERK pathway plus treatment with LY294002 in the MCF-7 cells. All in all, these results suggest that MDA-MB-231 cells are sensitive to the ERK inhibitor, whereas MCF-7 cells are sensitive to the PI3K inhibitor.

To prove whether the slight decrease in cell viability after knockdown of SIAH2 expression was caused by feedback activation of the PI3K pathway in the MDA-MB-231 cells, the cells were transfected with SIAH2 siRNA and then treated with the PI3K inhibitor (LY294002). It was found that cell viability was reduced significantly (Fig. 7). Similarly, the 

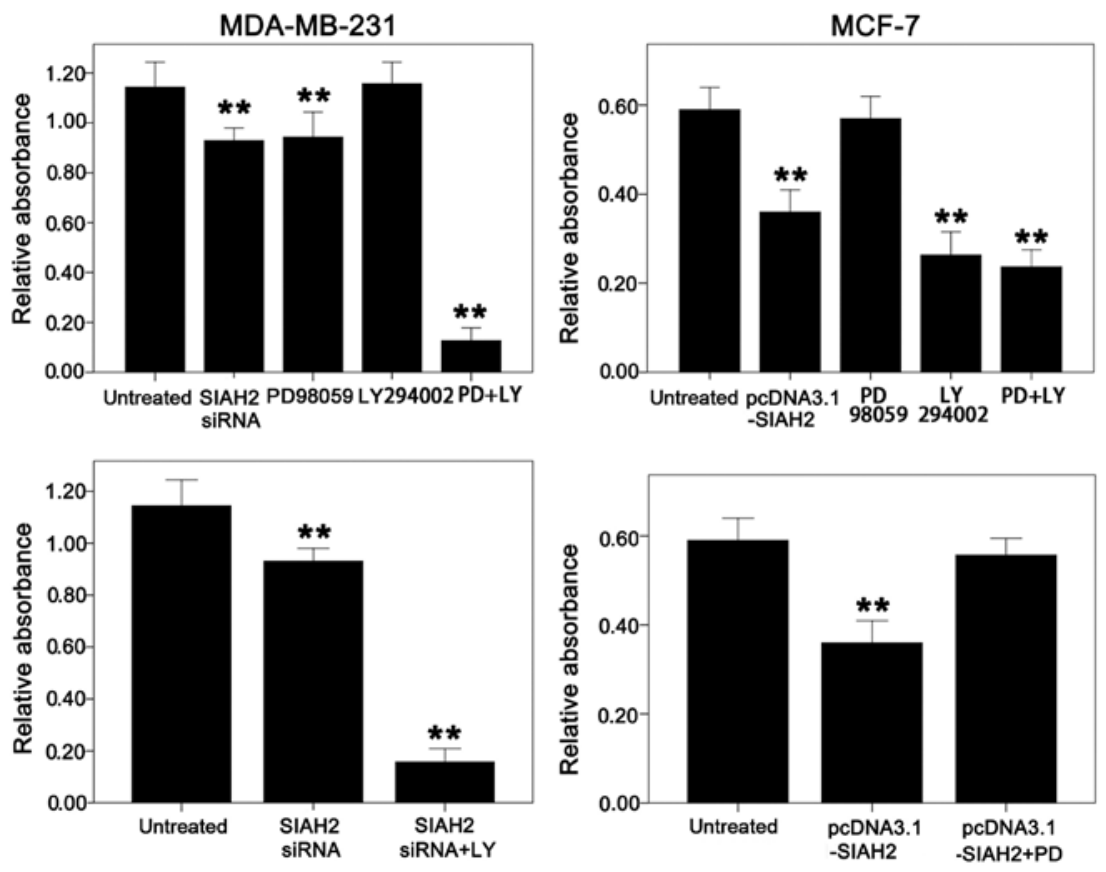

Figure 7. Effect of SIAH2 overexpression or knockdown and treatment with the ERK or PI3K inhibitors on the regulation of breast cancer cell viability. MDA-MB-231 or MCF-7 cells were transfected with SIAH2 cDNA or siRNA and treated with the ERK (PD98059) or PI3K inhibitor (LY294002) and then subjected to a tumor cell viability assay. ${ }^{* *} \mathrm{P}<0.01$.
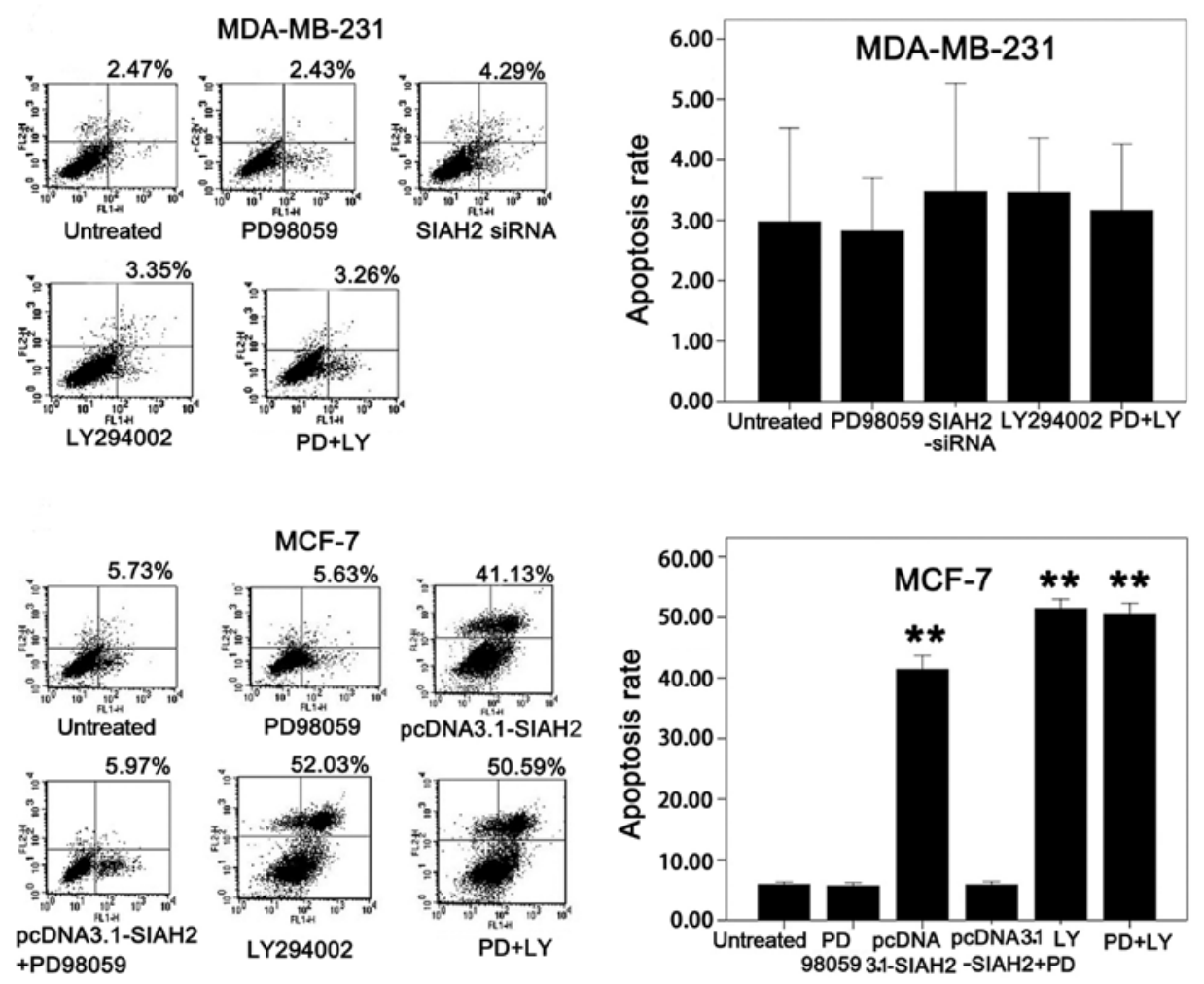

Figure 8. Effect of SIAH2 overexpression or knockdown and treatment with the ERK or PI3K inhibitors on the regulation of breast cancer cell apoptosis. MDA-MB-231 or MCF-7 cells were transfected with SIAH2 cDNA or siRNA and treated with the ERK (PD98059) or PI3K inhibitor (LY294002) and then subjected to a tumor cell viability assay. ${ }^{* *} \mathrm{P}<0.01$.

MCF-7 cells were transfected with SIAH2 cDNA and then treated with the ERK inhibitor (PD98059); it was found that with the recovery of p-AKT expression, cell viability was also recovered (Fig. 7).
Similar data were obtained in SIAH2 knockdown as well as treatment with the ERK and PI3K inhibitors on regulation of tumor cell apoptosis between MDA-MB-231 and MCF-7 cells (Fig. 8). 


\section{Discussion}

In the present study, the expression of the SIAH2 protein in normal, premalignant, and malignant breast tissues was analyzed for association with clinicopathological data from IBC patients. The effects of SIAH2 expression or knockdown on the regulation of breast cancer cell biology behavior and the underlying molecular events were then explored. It was found that expression of the SIAH2 protein was upregulated in IBCs compared to normal or DCIS tissues. SIAH2 expression was associated with a higher tumor nuclear grade and molecular classification of breast cancer subtypes. The in vitro data showed that manipulation of SIAH2 expression (overexpression or knockdown) led to 'cross-talk' of the ERK and PI3K pathways in different subtypes of breast cancer cell lines (luminal- vs. basal-like), which could be one of the mechanisms by which SIAH2 regulates viability, apoptosis, and invasion capacity in breast cancer cells.

SIAH2 protein is a ring finger E3 ubiquitin ligase involved in hypoxia response and regulation of the Ras/ Raf and $\mathrm{p} 38 / \mathrm{JNK} / \mathrm{NF}-\kappa \mathrm{B}$ signaling pathway. SIAH2 substrates include DCC (22), OBF-1 (23,24), TRAF2 (25), PHD1/3 (26,27), Vav1 (28), and Spry2 (29). SIAH2 substrates can interact with the SIAH2 protein in an AXVXP motifdependent or independent way to affect multiple aspects of cell functions, such as cell survival, mitochondrial biogenesis, and hypoxia and stress response. Thus, overexpression of the SIAH2 protein may lead to breast cancer development, which is consistent with our current data. Furthermore, our current study also demonstrated that SIAH2 expression was associated with tumor nuclear grade and molecular classification of breast cancer subtypes. Higher expression of SIAH2 protein led to higher IBC nuclear grade and contributed to basal-like breast cancer. A previous study also showed that SIAH2 was expressed in pancreatic, breast, lung, and cervical cancers and different tumor cell lines and that the level of SIAH2 expression increased with tumor cell malignant behavior (13).

Furthermore, our current data also showed that SIAH2 expression or knockdown led to 'cross-talk' of the ERK and PI3K pathways, which may be one of the mechanisms by which SIAH2 regulates viability, apoptosis, and invasion capacity in breast cancer cells. Indeed, alteration of multiple signaling pathways has been shown to occur in breast cancer, including the commonly observed MAPK and PI3K pathways (30). Previous studies revealed that SIAH2-regulated cell proliferation and inhibition of apoptosis occurred through activation of the ERK pathway $(13,16,17)$. SIAH2 was also closely related to HIF-1 $\alpha$; an increase in SIAH2 activity under a hypoxic condition is able to upregulate HIF- $1 \alpha$ level and, in turn, promote expression of its downstream target genes, including VEGF, c-Met, CXCR4 and lysine oxidase, for tumor growth and metastasis (31).

Moreover, our current study showed differential effects of SIAH2 expression or knockdown on the regulation of cell viability, apoptosis, and invasion capacity of luminal-like and basal-like breast cancer cells (MDA-MB-231 and MCF-7 cells, respectively). Furthermore, it was also found that overexpression of SIAH2 in the MDA-MB-231 cell line had no effect on p-ERK, p-AKT or HIF-1 $\alpha$ expression, whereas knockdown of SIAH2 expression was able to reduce the level of p-ERK, but induce p-AKT and HIF-1 $\alpha$ levels. In contrast, overexpression of the SIAH2 protein in the MCF-7 cell line increased the p-ERK level, but decreased the p-AKT and HIF-1 $\alpha$ levels, whereas knockdown of SIAH2 expression slightly decreased p-ERK expression, but had no effects on the p-AKT level. These data suggest that the role of SIAH2 in different breast cancer cell lines may be based on differential gene expression profiles in the given cell lines. In addition, our ex vivo data showed that SIAH2 may function differently in different molecular subtypes (e.g., luminal- vs. basal-like type of breast cancer) of breast cancer.

In addition, our current study assessed that the effect of SIAH2 on breast cancer cell proliferation occurring through activation of the ERK and PI3K pathways by transfecting breast cancer cells with SIAH2 shRNA and then treating them with the ERK and/or PI3K inhibitors (PD98059 and/or LY294002, respectively). Our results showed that SIAH2 regulated the MCF-7 luminal-like breast cancer cell line growth mainly through apoptosis in a PI3K-dependent manner, whereas suppression of the MDA-MB-231 basal-like tumor cell line growth was mainly regulated by the ERK pathway with little or no involvement of apoptosis. Indeed, ERK is a member of the MAPK family and plays a crucial role in the regulation of cell growth and division. In the ERK pathway, Ras acts as an upstream activation protein to form the Ras-Raf-MEK-ERK pathway. Spry2, an inhibitor of the Ras/Raf signaling pathway, is a SIAH2 substrate and plays an important role in cancer development. A previous study showed that changes in Spry2 expression are associated with downregulation of Ras signaling and that knockdown of SIAH2 expression upregulated Spry2 and weakened Ras signaling (14). Furthermore, $\mathrm{PI} 3 \mathrm{~K} / \mathrm{AKT}$ is an important pathway in mediating the survival signal in cells and inhibition of AKT may trigger feedback that activates other signaling pathways to maintain cell survival. It has been confirmed that after inhibition of AKT signaling, expression of the tyrosine kinase receptor is upregulated and mTORC 2 is activated in a feedback manner to activate MAPK activity, while inhibition of mTOR downstream of AKT by rapamycin or temsirolimus can also activate the PI3K/AKT pathway in a feedback manner. Our current study showed cross-reaction or a competitive relationship between the ERK and PI3K pathways and SIAH2 regulation of breast cancer invasion mainly depended on activation of the PI3K pathway. Thus, an unsatisfactory efficacy of a single MEK or AKT inhibitor on breast cancer may be associated with feedback activation, which may be the major obstacle in the development of anticancer drugs.

However, our current study is a proof-of-principle and additional research needs to be performed to confirm our results. Future studies are required to study additional cell lines to investigate SIAH2 in classifying breast cancer molecularly and developing the protein as a biomarker for early or differential diagnosis of breast cancer.

\section{Acknowledgements}

We thank Dr Ze'ev Ronai of The Burnham Institute (La Jolla, CA, USA) for the SIAH2 expression vector (pcDNA3.1-flag-SIAH2). 


\section{References}

1. Perou CM, Sørlie T, Eisen MB, van de Rijn M, Jeffrey SS, Rees CA, Pollack JR, Ross DT, Johnsen H, Akslen LA, et al: Molecular portraits of human breast tumours. Nature 406: 747-752, 2000.

2. Dent R, Trudeau M, Pritchard KI, Hanna WM, Kahn HK, Sawka CA, Lickley LA, Rawlinson E, Sun P and Narod SA: Triple-negative breast cancer: Clinical features and patterns of recurrence. Clin Cancer Res 13: 4429-4434, 2007.

3. West M, Blanchette C, Dressman H, Huang E, Ishida S, Spang R, Zuzan H, Olson JA Jr, Marks JR and Nevins JR: Predicting the clinical status of human breast cancer by using gene expression profiles. Proc Natl Acad Sci USA 98: 11462-11467, 2001.

4. Carey LA, Perou CM, Livasy CA, Dressler LG, Cowan D, Conway K, Karaca G, Troester MA, Tse CK, Edmiston S, et al: Race, breast cancer subtypes, and survival in the Carolina Breast Cancer Study. JAMA 295: 2492-2502, 2006.

5. Kreike B, van Kouwenhove M, Horlings H, Weigelt B, Peterse H, Bartelink $\mathrm{H}$ and van de Vijver MJ: Gene expression profiling and histopathological characterization of triple-negative/basal-like breast carcinomas. Breast Cancer Res 9: R65, 2007.

6. Abd El-Rehim DM, Ball G, Pinder SE, Rakha E, Paish C, Robertson JF, Macmillan D, Blamey RW and Ellis IO: High-throughput protein expression analysis using tissue microarray technology of a large well-characterised series identifies biologically distinct classes of breast cancer confirming recent cDNA expression analyses. Int J Cancer 116: 340-350, 2005.

7. Savage K, Leung S, Todd SK, Brown LA, Jones RL, Robertson D, James M, Parry S, Rodrigues Pinilla SM, Huntsman D, et al: Distribution and significance of caveolin 2 expression in normal breast and invasive breast cancer: An immunofluorescence and immunohistochemical analysis. Breast Cancer Res Treat 110 : 245-256, 2008.

8. Kim JY, Ahn HJ, Ryu JH, Suk K and Park JH: BH3-only protein Noxa is a mediator of hypoxic cell death induced by hypoxia-inducible factor 1 $\alpha$. J Exp Med 199: 113-124, 2004.

9. Oliver PL, Bitoun E, Clark J, Jones EL and Davies KE: Mediation of Af4 protein function in the cerebellum by Siah proteins. Proc Natl Acad Sci USA 101: 14901-14906, 2004.

10. Habelhah H, Laine A, Erdjument-Bromage H, Tempst P, Gershwin ME, Bowtell DD and Ronai Z: Regulation of 2-oxoglutarate (alpha-ketoglutarate) dehydrogenase stability by the RING finger ubiquitin ligase Siah. J Biol Chem 279: 53782-53788, 2004.

11. Carthew RW and Rubin GM: seven in absentia, a gene required for specification of R7 cell fate in the Drosophila eye. Cell 63: 561-577, 1990

12. Hu G, Chung YL, Glover T, Valentine V, Look AT and Fearon ER: Characterization of human homologs of the Drosophila seven in absentia (sina) gene. Genomics 46: 103-111, 1997.

13. Schmidt RL, Park CH, Ahmed AU, Gundelach JH, Reed NR, Cheng S, Knudsen BE and Tang AH: Inhibition of RAS-mediated transformation and tumorigenesis by targeting the downstream E3 ubiquitin ligase seven in absentia homologue. Cancer Res 67: 11798-11810, 2007.

14. Qi J, Nakayama K, Gaitonde S, Goydos JS, Krajewski S, Eroshkin A, Bar-Sagi D, Bowtell D and Ronai Z: The ubiquitin ligase Siah2 regulates tumorigenesis and metastasis by HIF-dependent and -independent pathways. Proc Natl Acad Sci USA 105: 16713-16718, 2008.

15. Ahmed AU, Schmidt RL, Park CH, Reed NR, Hesse SE, Thomas CF, Molina JR, Deschamps C, Yang P, Aubry MC, et al: Effect of disrupting seven-in-absentia homolog 2 function on lung cancer cell growth. J Natl Cancer Inst 100: 1606-1629, 2008
16. Finn RS, Dering J, Ginther C, Wilson CA, Glaspy $\mathrm{P}$, Tchekmedyian $\mathrm{N}$ and Slamon DJ: Dasatinib, an orally active small molecule inhibitor of both the src and abl kinases, selectively inhibits growth of basal-type/"triple-negative" breast cancer cell lines growing in vitro. Breast Cancer Res Treat 105: 319-326, 2007.

17. Kao J, Salari K, Bocanegra M, Choi YL, Girard L, Gandhi J, Kwei KA, Hernandez-Boussard T, Wang P, Gazdar AF, et al: Molecular profiling of breast cancer cell lines defines relevant tumor models and provides a resource for cancer gene discovery. PLoS One 4: e6146, 2009.

18. Neve RM, Chin K, Fridlyand J, Yeh J, Baehner FL, Fevr T, Clark L, Bayani N, Coppe JP, Tong F, et al: A collection of breast cancer cell lines for the study of functionally distinct cancer subtypes. Cancer Cell 10: 515-527, 2006.

19. Payne RE, Yagüe E, Slade MJ, Apostolopoulos C, Jiao LR, Ward B, Coombes RC and Stebbing J: Measurements of EGFR expression on circulating tumor cells are reproducible over time in metastatic breast cancer patients. Pharmacogenomics 10 : $51-57,2009$.

20. Charafe-Jauffret E, Ginestier C, Monville F, Finetti P, Adélaïde J, Cervera N, Fekairi S, Xerri L, Jacquemier J, Birnbaum D, et al: Gene expression profiling of breast cell lines identifies potential new basal markers. Oncogene 25: 2273-2284, 2006.

21. Nielsen TO, Hsu FD, Jensen K, Cheang M, Karaca G, Hu Z, Hernandez-Boussard T, Livasy C, Cowan D, Dressler L, et al: Immunohistochemical and clinical characterization of the basal-like subtype of invasive breast carcinoma. Clin Cancer Res 10: 5367-5374, 2004.

22. Hu G, Zhang S, Vidal M, Baer JL, Xu T and Fearon ER: Mammalian homologs of seven in absentia regulate DCC via the ubiquitin-proteasome pathway. Genes Dev 11: 2701-2714, 1997.

23. Boehm J, He Y, Greiner A, Staudt L and Wirth T: Regulation of BOB.1/OBF.1 stability by SIAH. EMBO J 20: 4153-4162, 2001.

24. Tiedt R, Bartholdy BA, Matthias G, Newell JW and Matthias P: The RING finger protein Siah-1 regulates the level of the transcriptional coactivator OBF-1. EMBO J 20: 4143-4152, 2001.

25. Habelhah H, Frew IJ, Laine A, Janes PW, Relaix F, Sassoon D, Bowtell DD and Ronai Z: Stress-induced decrease in TRAF2 stability is mediated by Siah2. EMBO J 21: 5756-5765, 2002.

26. Nakayama K, Frew IJ, Hagensen M, Skals M, Habelhah H, Bhoumik A, Kadoya T, Erdjument-Bromage H, Tempst P, Frappell PB, et al: Siah2 regulates stability of prolyl-hydroxylases, controls HIF1 $\alpha$ abundance, and modulates physiological responses to hypoxia. Cell 117: 941-952, 2004.

27. Nakayama K, Gazdoiu S, Abraham R, Pan ZQ and Ronai Z: Hypoxia-induced assembly of prolyl hydroxylase PHD3 into complexes: Implications for its activity and susceptibility for degradation by the E3 ligase Siah2. Biochem J 401: 217-226, 2007.

28. Germani A, Romero F, Houlard M, Camonis J, Gisselbrecht S, Fischer S and Varin-Blank N: hSiah2 is a new Vav binding protein which inhibits Vav-mediated signaling pathways. Mol Cell Biol 19: 3798-3807, 1999.

29. Nadeau RJ, Toher JL, Yang X, Kovalenko D and Friesel R: Regulation of Sprouty2 stability by mammalian Seven-inAbsentia homolog 2. J Cell Biochem 100: 151-160, 2007.

30. Hu Z, Fan C, Oh DS, Marron JS, He X, Qaqish BF, Livasy C, Carey LA, Reynolds E, Dressler L, et al: The molecular portraits of breast tumors are conserved across microarray platforms. BMC Genomics 7: 96, 2006.

31. Khurana A, Nakayama K, Williams S, Davis RJ, Mustelin T and Ronai Z: Regulation of the ring finger E3 ligase Siah2 by p38 MAPK. J Biol Chem 281: 35316-35326, 2006. 